\title{
EVALUATING THE INFLUENCE OF DIFFERENT SOFT LINERS RETAINING MINI IMPLANT SUPPORTED MANDIBULAR OVER DENTURE ON THE MARGINAL BONE HEIGHT
}

\author{
Amr Salah El-Din* and Ahmed M. Osama Ahmed Shawky **
}

\begin{abstract}
Introduction: Using a soft liner-retained implant-supported overdenture offers the restorative dentist a treatment option when the number, location, or angulation of dental implants placed may differ from the original treatment plan. The aim of the present study was to evaluate the marginal bone height changes in mini-implant supported overdentures using different retaining denture softliners.
\end{abstract}

Patients \& Methods: Twenty-one completely edentulous cases were selected for this study. The patients were allocated into one of the three treatments groups. In group I the lower overdenture was relined with "acrylic based soft liner"; group II the lower overdenture was relined with "silicon based soft liner", while in group III: the lower overdenture was relined with 'Retention Sil 200". Patients in all groups received CBCT immediately after the implant loading, 6 months and 12 months after insertion of partial overdenture. Each implant was evaluated for the marginal bone level.

Results: The Silicon, Retention Sil 200 and acrylic based soft liners showed a statistical significant difference in the amount of bone resorption.

Conclusion: the current study concluded that Silicon and acrylic based soft liners show significant difference in their effect on the supporting bone due to stresses transmitted to miniimplant retained mandibular over dentures. Retention. Sil resilient liners cannot be considered as a permanent mean of retention for mini implant retained mandibular but it shows high success for short- and medium-term management.

KEY WORDS: overdentures, mini-implants, soft liners, acrylic base soft-liners, silicon based soft-liners.

* Lecturer of Removable Prosthodontics, Faculty of Dentistry, Fayoum University.

** Associate professor of Removable Prosthodontics, Faculty of Dentistry, Ain shams University. 


\section{INTRODUCTION}

Retention and stability problems of the mandibular prosthesis often cause complaints of masticatory function in complete denture wearers. Complete denture wearers. Complete denture wearers needed on average four times, six times, and even eight times the number of chewing strokes dentate persons to achieve the same degree of pulverization ${ }^{(1)}$

The loss of bone first causes decreased bone width followed by bone height; the remaining narrow residual ridge often causes discomfort when the thin overlying tissues are loaded under the denture ${ }^{(2)}$

Loss of bone in mandible is not limited to alveolar bone, portions of the basal bone may resorbed where severe resorption causes both mental foramen become dehiscent and serve as part of the support area of the denture resulting in acute pain and parasthesia of the lower lip and the body of the mandible is at increased risk of fracture even under low impact forces. ${ }^{(3,4)}$

Denture wearers suffer from soft tissue complications as denture stomatitis, traumatic ulcers, angular cheilitis, irritation-induced hyperplasia, altered taste perception, and burning mouth syndrome. ${ }^{(5)}$

The implant retained over denture has been proposed as the standard of care for the restoration of the edentulous mandibular arch. Implant supported prosthesis are today often used in rehabilitation of partially or totally edentulous patients. ${ }^{(6)}$

Evidence currently available suggests that the restoration of the edentulous mandible with conventional complete denture, is no longer the first treatment of choice, and that rehabilitation with mini-dental implant retained overdenture should be considered a possible(the first) treatment alternative for the edentulous mandible. ${ }^{(7)}$ In comparison with conventional diameter implants, mini dental implants (MDI) are cost effective, have fewer complications during flapless implant placement, and can be used in edentulous arches with minimal remaining bone in a facial-lingual dimension to avoid bone graft. MDIs also have the advantages of single stage conventional diameter implants including; short healing time, minimal postoperative discomfort, and immediate restoration of mastication and esthetics for patients during the healing period. ${ }^{(8)}$

One of the factors which influences the amount of force transferred to the implant is the choice of the attachment used in connecting the denture to the implant. ${ }^{(9)}$ The load transfer mechanism of the implant system is altered significantly by the type of attachment used. ${ }^{(10)}$

Resilient denture liners have found increasing favor in several applications in prosthetic dentistry, including use with dental implants for retention. ${ }^{(11)}$

A soft liner may be defined as "soft elastic and resilient material forming all or, a part of the soft tissue- contacting surface of a removable denture. Soft liners are mostly used for reducing local point pressures". They usually act as a cushion to distribute the masticatory forces transmitted to the underlying tissues but they do not necessarily decrease the force transmitted. ${ }^{(12 \& 13)}$

Also, soft liner may be defined as "elastomer polymer used in the prevention of chronic soreness from dentures and the preservation of the supporting structures. ${ }^{(14)}$

There are two main types of these materials: plasticized acrylics and silicone elastomers, differing in the percentage of cross-linking agents, catalysts, and fillers which are available in auto polymerizing and heat polymerizing forms. Using a soft liner-retained implant-supported overdenture offers the restorative dentist a treatment option when the number, location, or angulation of dental implants placed may differ from the original treatment plan. ${ }^{(15)}$

Soft acrylic resin are composed of polyethy methacrylate and monomer liquid of higher methacrylate with a phthalate plastizer. Plasticized acrylics are made resilient by addition of oily or alcohol- type plasticizers or by copolymerization with monomer 
units. The hydrophilic polymer is a mixture of poly ethylene glycol methacrylate with diacetine. ${ }^{(13)}$

These materials are two- paste systems. Atypical "catalyst paste" is a mixture of vinyl- terminated polydimethylsiloxanes with a platinum catalyst. The "base paste" consists of vinyl- terminated polydimethylsiloxanes with hybrid- terminated polydimethylsiloxanes. The hydrosilylation reaction begins after both components are mixed, and the addition of $\mathrm{Si}-\mathrm{H}$ from the hybrid functional siloxanes results in bonds across the unsaturated bonds, forming vinyl functional siloxanes. This curing reaction does not produce by- products. ${ }^{(16)}$

Retention. Sil was introduced based in its chemical composition on Polyvinylsiloxane (PVS) that has three options according to the detachment force desired $(200,400,600 \mathrm{gf})$. $^{(17)}$

Clinical observations promote retention.sil as a suitable matrix product for implant overdenture, due to its positive biological, physical and retention properties. ${ }^{(18)}$

Retention.sil material can be used as silicone matrix for implant overdenture, in place of the attachment system component in the denture's base, as it has an adequate short-term and medium-term behavior. Retention.sil 200 is most appropriate during the osseointegration phase. Retention.sil 400 is best suited in the later phases and offers a better retention which remains almost constant over time with different attachment systems (e.g., ball or Locator attachment system). ${ }^{(18)}$

The aim of the present study was to evaluate the marginal bone height changes in mini-implant supported overdenture using different retaining denture soft-liners.

\section{Radiographic techniques for implant evaluation}

The accuracy of determining marginal bone height changes around osseointegrate implants depend on the validity of comparing serial films and reliability of measurements reliable comparison of subsequent radiographs is only possible when the technique of recording and analysis is reproducible, thus allowing linear and volumetric changes in bone support to be monitored. ${ }^{(19)}$

Radiographic evaluation of the implant is used in three phases, one is termed pre-prosthetic implant imaging where the objective of this phase to determine the quality, quantity and angulation of the bone, the relationship of critical structures to the prospective implant sites, the presence of any disease at the proposed surgery sites. ${ }^{(19)}$

The second phase is termed surgical and interventional implant imaging where its objectives are to evaluate the surgery sites during and immediately after surgery, assist in optimal position and orientation of dental implants and ensure abutment position the third phase is called post-prosthetic implant imaging where its objectives are to evaluate long term maintenance of implant rigid fixation and function including crestal bone level around each implant. ${ }^{(20)}$

\section{MATERIALS AND METHODS}

Twenty-one completely edentulous cases were selected from the Outpatient Clinic of the Prosthodontic Department, Faculty of Oral and Dental Medicine, fayoum University with proper oral hygiene, well educated regarding the use of over denture and free from any systemic diseases that affect ossteo integration or bone resorption around the implant.

Completed medical and dental history was taken for all patient and alveolar bone height was evaluated using CBCT. Patients were fully informed about the treatment procedures, follow-up examinations and potential complications of surgical procedures. Informed consent was obtained from each patient prior to participation in the study.

Study was conducted in accordance with Helsinki Declaration of 1975 for medical studies as revised in 2000 .

A diagnostic Cone Beam Computed Tomography (CBCT) images using i-CAT was done to evaluate bone volume (width) at the proposed implant site. 
It was used to guide the insertion of the four implants in the symphyseal area between the mental foramina.

The position of most distal implant on each side was marked on the radiographic stent $5 \mathrm{~mm}$ mesial to the mental foramina. The position of the other two implants were marked on the radiographic stent with nearly equal distances with at least $6 \mathrm{~mm}$ between each two marks to represent the prospective implant sites during the initial implant drilling. Four equidistant holes were drilled in the stent opposite to the proposed position of each implant. The surgical stent was then tried intra-orally. The stent was sterilized and stored until needed.

All the clinical and laboratory steps of complete denture construction were done, and the patients received an acrylic complete denture and then the Patients were recalled after performing the needed post insertion adjustments to the dentures for implants insertion.

All patients received Four mini dental implants (machined, textured and acid etched surface treatment) ${ }^{*}$ screw type one piece with $2.4 \mathrm{~mm}$ in diameter and $13 \mathrm{~mm}$ in length in the symphyseal area between the mental foramina. fig (1)

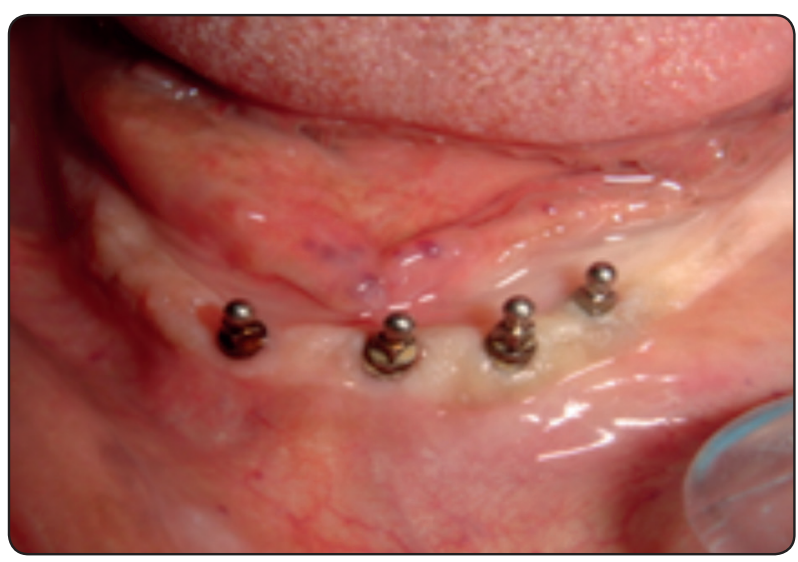

Fig. (1)
On the day of the surgery, inferior alveolar nerve block anesthesia was given to both sides of the arch beside infiltration anesthesia in the symphyseal area of the mandible. The surgical stent was placed in the patient's mouth, the entry points for each implant are marked on the patient's tissue via a tissue punch.

A surgical drill of $1.3 \mathrm{~mm}$ diameter was used to drill through the bone at approximately 800-1000 RPM associated with constant continuous flow of copious amounts of saline solution by using a delicate up and down pumping action.

The sterile vial containing the single piece mini implant of $2.4 \mathrm{~mm}$ diameter was opened and the implant was transferred to the osteotomy by the vial cap and stabilized in the osteotomy.

The Winged Thumb Wrench was used to finger screw the implant into the hole made in the bone until too much resistance was met to screw the implant. Specially designed ratchet wrench with torque indicator was used until the implant is fully seated. The neck of the mini dental implant was fully inserted into soft tissue (attached gingiva) so that only the abutment head protruded into the oral cavity.

The implant positions were marked on the fitting surface of the mandibular by marking the heads of the O-balls by a marker.

For all patients, the denture was reduced in the fitting surface of the denture using a round bur, so that the denture fits passively onto the newly placed implants. The denture was checked to fit over the implants without interfering with the original fit of the denture.

The selected cases were recalled after one week from implant insertion, and randomly divided into three equal groups:

Group I: Lower over denture was prepared to be relined with "acrylic base soft liner"**. The lower denture was rinsed, dried and then a separating medium was painted to all the areas were the relining

\footnotetext{
* Mini implant 2.4mm diameter, 3M ESPE, Germany.

** COE-Soft ${ }^{\mathrm{TM}}$ Resilient Denture Liner - Liquid - GC America, Inc.
} 
is not desired .mixing the soft liner powder and liquid according to the manufacture instruction and then dispersed into the fitting surface, the prosthesis was inserted and the patient was instructed to close gently at centric occlusion for 15 minute until full polymerization take place and then excess material was removed with surgical blade

Group II: Lower over dentures were prepared to be relined with a "silicone based soft liner ". A thin coat of adhesive was applied and allowed to dry about 1minute.

Soft reline material was extruded into the tissue surface of the denture by using the gun*. The denture was placed in the patient's mouth and the patient was asked to close his mouth in centric occlusion for 7 minute.

Denture was removed and excess material was trimmed with a surgical blade.

Group III: The Lower over dentures were prepared to be relined with a "Retention Sil 200"*** for retaining their mandibular over denture. The fitting surface of the denture was conditioned with the Multi-Sil primer and the retention.sil was filled up to the top by injection from its auto injected cartilage.

The prosthesis was inserted and the patient closed his mouth at centric occlusion 3 minutes.

After $3 \mathrm{~min}$, the prosthesis was removed and the excess was removed with a surgical blade.fig (2)

The denture was returned to the patient's mouth, complete seating, comfort and ease of placement were assured and any necessary adjustments were carried out to eliminate any occlusal interference.

Patients were instructed to maintain strict oral and denture hygiene measures and to keep the denture in place for the first 48 hours after placement to prevent tissue overgrowth

\footnotetext{
* Secure soft reline kit 3MTMESPETM,Germany

** Bredent Medical Gm Bh \& Co.KG.Germany
}

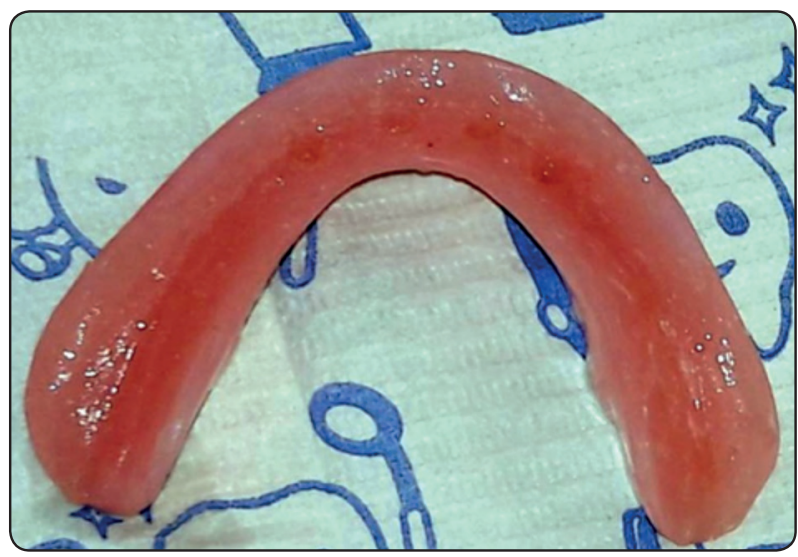

Fig. (2)

Patients in all groups received CBCT immediately after the implant loading, 6months and 12 months after insertion of partial overdenture. Each implant was evaluated for the marginal bone level. The implant shoulder was used as a reference point, and the distance to the first bone contact mesially and distally was measured from the CBCT using Invivo 5 software (version 5.3 Anatomage, San Jose, USA) were used for the assessment of crestal bone level, peri-implant bone quality and bone surrounding implant apices. The radiographs were compared with base line radiographs. The marginal bone level was assessed at mesial and distal side of fixture on the radiographs. The height of the alveolar bone on mesial and distal sides of the implant was measured as follow: Average bone height $=($ Mesial bone height + Distal bone height)/2.

\section{Statistical Analysis}

Data were fed to the computer and analyzed using IBM SPSS software package version 20.0. Data were fed to the computer and analyzed using IBM SPSS software package version 20.0. (Armonk, NY: IBM Corp). The Kolmogorov-Smirnov, Shapiro and D'agstino tests were used to verify the normality of distribution of variables, Comparisons between groups for categorical variables were assessed using 


\section{Chi-square test (Fisher or Monte Carlo). Student}

t-test was used to compare two groups for normally distributed quantitative variables. Mann Whitney test was used to compare between two groups for abnormally distributed quantitative variables. Significance of the obtained results was judged at the $5 \%$ level.

\section{RESULTS}

A total of twenty- one patients was recruited in the present study and they are equally allocated by random distribution into 3 groups $(n=7$ patients per group). Seventeen patients were male (80.81\%) and Four were females $(19.09 \%)$. Patient aged ranged from 66-75 years (mean 69 \pm 7.35 ). All patients completed the follow-up examination period, therefore no dropout in the study data. Bone height change in the studied groups during the follow up period

The surgical procedure was performed for all groups without any complication in all patients. All implants in all groups healed without any complications until the final follow up visits. No signs of peri-implantitis were recorded throughout the 12 months follow-up period. Moreover, no patients reported any adverse actions such as pain or altered sensation in the treated areas during follow up period.
The changes of bone height showed no statistical significant difference between the groups at $6^{\text {th }}$ months follow-up. While at $12^{\text {th }}$ months postoperative, there was a statistically significant change between the groups (Table 1)

Regarding changes by time within each group, group I (acrylic based liners) showed a statistically significant decrease between $6^{\text {th }}$ months and $12^{\text {th }}$ month postoperative. On the other hand, Group II \& III showed no statistically significant difference in bone height between $6^{\text {th }}$ months and $12^{\text {th }}$ months postoperative. (Table 1)

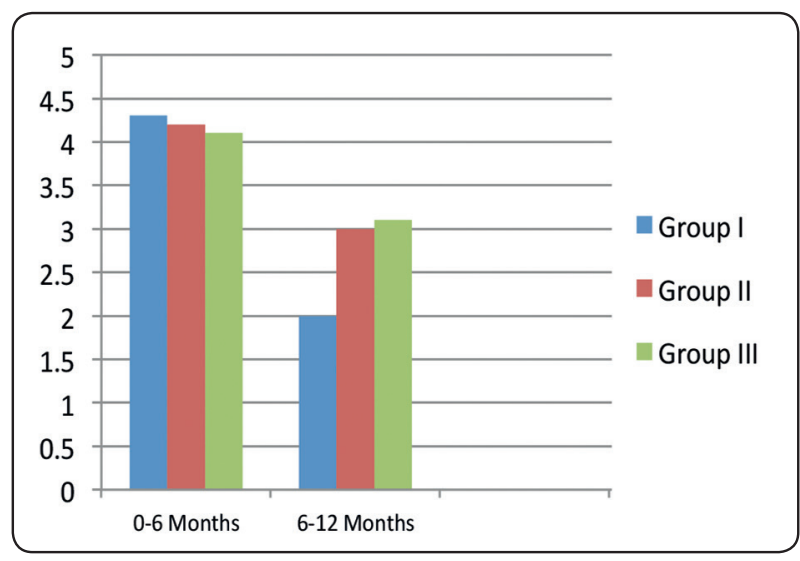

Fig. (3): Mean values of bone height change of two studied groups at two follow up periods.

TABLE (1): The mean value and standard deviation of crestal bone height change around the implants for Group 1 and Group 2 during the follow up period.

\begin{tabular}{|l|l|l|l|l|}
\hline & Group I & Group II & Group III & P-value \\
\hline At 6 $^{\text {th }}$ month & $0.64 \pm 0.12$ & $0.71 \pm 0.13$ & $0.69 \pm 0.15$ & $\mathbf{0 . 2 1 4}$ \\
\hline At $\mathbf{1 2}^{\text {th }}$ month & $1.1 \pm 0.1$ & $0.81 \pm 0.14$ & $0.71 \pm 0.13$ & $\mathbf{0 . 0 0 1}$ \\
\hline$P$-value (within group) & $<\mathbf{0 . 0 0 1 *}$ & $\mathbf{0 . 3 2 1}$ & $\mathbf{0 . 4 2 1}$ & \\
\hline
\end{tabular}

Qualitative data were described using number and percent, while normally quantitative data was expressed in mean $\pm S D$, abnormally distributed data was expressed in median (Min. - Max.) 


\section{DISCUSSION}

All the patients that were included in this study should had a period of at least six months from the time of the last extraction or any intra-oral surgery before the beginning of the study to make sure of the proper healing. ${ }^{(21)}$

The mandibular arch was selected for implant placement to help in solving some problems such as retention, stability and support of the superstructure. ${ }^{(22)}$

Mini implants may be relatively easy to place and restore with appropriate preoperative data collection, such as osseous ridge contour and gingival quantity. Additionally, there is some evidence that in highly selected situations, mini dental implants can be used to support fixed partial or complete dentures. ${ }^{(23)}$

Mini implants may be immediately loaded in the appropriate osseous situations and may provide an alternative treatment if osseous conditions preclude a standard sized implant approach. ${ }^{(24)}$

Proper patients' selection is very important for success of dental implant. Patients should be free from any systemic diseases (cardiac disease, diabetes mellitus, and debilitating diseases) that may affect the rate of bone resorption, gingival health, healing processes and the prognosis of implant-overdenture. ${ }^{(25)}$

Also; patient with insufficient bone volume, Cases with abnormal ridge relations, or Parafunctional activities as bruxism in which the magnitude of force is increased, and the direction of the occlusal forces are more horizontal than axial to the implants. Angles' class I jaw relationship patients were selected to avoid abnormal forces which are exerted on the expected implant site, thus extra load on the implant can lead to bone loss, and higher rates of implant failure. Abnormal tongue size and/or position, high labial frenum or tongue-tie require prosthetic and surgical treatment, all such cases were excluded. (26)
Tissue punch was used to punch oral mucosa at the site of each implant guided by surgical stent. Then, pilot drill $1.1 \mathrm{~mm}$ was used to drill through bone to about two third the mini implant length as Mini dental implants have the advantage of expanding the bone as they are placed, producing immediate stabilization in most situations with minimal bone removal, as well as they require only a narrow-diameter osteotomy that does not extend to the full depth of the implant, as well as they are usually loaded on the day of placement, reducing the length of the treatment period. ${ }^{(27)}$

The mini implant was placed at site of drilling by its cap, then finger wrench was used to screw the mini implant into its bony position. Ratchet wrench was used to finish the procedure of implant placement. $30-35 \mathrm{~N} / \mathrm{cm}$ fixation force is sufficient to achieve primary stability. ${ }^{(27)}$

Lower denture was modified by grinding the under surface to accommodate the implant heads without rocking or occlusal interference. Soft lining material specific for each group was applied and patient was instructed to close in centric occlusion until material setting was achieved according to manufacture instructions to avoid increase in previously recorded vertical dimension.

Two types of silicon based soft liner was used in (group II and III) and acrylic based soft liner was used in (group I). Each material was applied on the fitting surface of the implant- supported mandibular over dentures.

All of the investigated cases in this study showed changes radiographically and cllincally during the whole follow up period, these changes could be logically explained as they could be considered as a biological response to the insertion of mandibular implant supported over denture. The clinical outcome of the present study demonstrated some differences in the outcome between 2 groups after 12 months follow up. 
In this study the overdenture was retained by four mini implant that placed in the inter-foraminal region and the soft tissue covering the edentulous area posteriorly.

The result of this study showed that the amount of crestal bone resorption of group I patients (acrylic group) was more than the amount of crestal bone resorption of group II and III patients (silicon group) as showed by radiographic evaluation during the 12 months follow up period, and this may be due the difference in resiliency of the soft liner used. In group I (acrylic group) the resiliency of the acrylic soft liner may be decreased due to leaching out of the plasticizers and residual monomer ${ }^{(28 \& 29)}$. So it doesn'tcompensate the difference in the resiliency of the soft tissue overlaying the edentulous area posteriorly.

Resilient denture liners have found increasing favor in several applications in prosthetic dentistry, including their use with dental implants for retention. When used as a method of retention for implant-retained overdenture, these liners are wear resistant, partially obturate the space under the bar, absorb energy, distribute masticatory forces to the implants and edentulous ridge and provide greater latitude of movement and comfort to the patient. It was found that resilient denture liners offer more retention, which even when diminished after multiple insertions, was still greater than with bars and clips ${ }^{(30)}$

Soft liner female housing continuously cleanses the abutments during denture insertion and removal and prevents plaque accumulation regardless of oral hygiene practice by patients.

Resilient liner housing completely obturates the space around the abutment, thereby, it minimizes plaque and microbial adhesion that cause periimplant tissue inflammation, bone loss and pocket formation.

Recent studies considered that resilient denture liner materials can be useful for tissue-supported implant-retained overdenture. The use of resilient silicone lining material for retention resulted in a considerable decrease in the stresses transmitted to the implant and peri-implant bone compared to metal housing group. ${ }^{(31)}$

Shock-absorbing ability of soft liner reduces the stress applied to the implants which in turn reduces peri-implant bone loss. ${ }^{(32)}$

Retention.sil material can be used as silicone matrix for implant overdenture, in place of the attachment system component in the denture's base, as it has an adequate short-term and medium-term behaviour. Retention.sil 200 is most appropriate during the osseointegration phase. ${ }^{(32)}$

Using retension.sil as silicone matrix in the short and medium term is accompanied by low adherence of microbial plaque. It can thereby be preventively used during osseointegration period, in order to protect a vulnerable area. This is very important for treatment success. ${ }^{(33)}$

\section{CONCLUSION}

The current study concluded that Silicon and acrylic based soft liners show significant difference in their effect on the supporting bone due to stresses transmitted to mini-implant retained mandibular over dentures.

Silicon based soft liner is more favorable than acrylic based soft liner as a retentive mean for mini implant retained mandibular overdenture.

Retention. Sil resilient liners cannot be considered as a permanent mean of retention for mini implant retained mandibular but it shows high success for short and medium term management.

\section{REFERENCES}

1. Sonnessen L and Bakke M (2005): "Bite force in relation to occlusion. "Eur J Orthhos 27 (1):58-63.

2. Von Wowern (2001): General and oral aspects of osteoporosis a review. Clin Oral Invest; 5:71-82.

3. Tallgren A and Odent (2003): The continuing reducation of the residual alveolar ridges in complete denture wearers: 
A mixed-longitudinal study covering 25 years. The $\mathrm{J}$ Prosthet Dent; 89:427-435.

4. Christian Ulm and George Watzek (2011): Atrophy of the residual Alveolar Gidge Following Tooth Loss in a Hostrical Population. Oral Disease; $1: 1-26$.

5. MacEntee MI, Nolan A and Thomason JM (2004): Oral muscosal and osseous disorders in frail elders. Gerodontology; 21:78-84.

6. Awad MA, Lund JP, Shapiro SH, Locker D, Llemetti E, Chehade A, Savard A and Feine JS (2003): "Oral health status and treatment satisfaction with mandibular implant overdentures and conventional dentures: a randomized clinical trial in a senior population." Int J Prosthodont 16(4): 390-396.

7. Thomason JM, Kelly SA, Bendkowski A, Ellis JS.(2012): Two implant-retained overdentures - A review of the literature supporting the McGill and York consensus statements. J Dent:40:22-34.

8. Christensen GJ.(2009). The increased use of small-diameter implants. J Am Dent Assoc ;140:709-712.

9. Heckmann SM, Winter W. (2001): Overdenture attachment selection and the loading of implant and denturebearing area.Part 2: A methodical study using five types of attachment .Clin. Oral Impl. Res. 12; 640-647.

10. Meijer HJA, Kuiper JH, Starmans FJM and Bosman FJM. (1992): Stress distribution around dental implants: influence of superstructure, length of implant and height of mandible. J Prosthet Dent.68:96-102.

11. SudaratKiat-Amnuay, Zafrulla Khan, and Lawrence Gettleman (1999) :Overdenture retention of four resilient liners over an implant bar. J OF PROSTHETIC.81:95-102

12. Qudah S, Harrison A, Huggett R (1990): Soft lining materials in prosthetic dentistry: a review. Int J Prosthodont; pp.477-483.

13. Kawano F, Tada N, Nagao K, Matsumoto N (1991): The influence of soft lining materials on pressure distribution. $\mathrm{J}$ Prosthet Dent; pp. 567-575.

14. Qudah S, Harrison A, Huggett R (1990): Soft lining materials in prosthetic dentistry: a review. Int J Prosthodont; pp. 477-483.

15. Cain JR, and Mitchell DL. (1998): Soft liner-retained, implant-supported overdenture: a technical note,
International Journal of Oral and Maxillofacial Implants, vol. 13 , no. 6 ,pp: 857-860.

16. Colas A and Curtis J (2004): Silicone biomaterials: History andchemistry. In Biomaterial Science: An Introduction to Materials in Medicine, 2nd ed.; Ratner, B.D., Hoffman, A.S., Schoen, F.J., Lemmons, J.E., Eds.; Elsevier: Amsterdam, The Netherlands; pp. 83-85.

17. Preoteasa E, Imre M, Lerner H, Tancu AM and Preoteasa CT. (2015): Narrow Diameter and Mini Dental Implant Overdentures. PP. 978-953,.

18. Elena Preoteasa, Ana-Maria Cristina Tancu, Cristina Teodora Preoteasa (2014): Retention.sil as silicone matrices for implant overdenture, Carol Davila University of Medicine and Pharmacy, Bucharest, Romania, sky meeting.

19. Manz MC (2000): "Factors associated with radiographic vertical bone loss around implants placed in clinical study." Ann Periodontol 5(1): 137-151.

20. Federick DR and AA Caputo (1996): "Effect of overdenture renetion designs and implant orientations on load transfer characteristics." J Prosthet Dent 76(6): 624-632.

21. El-Guindy M., E.-T. M., Abdel Razzak Y. (1996): Longitudinal evaluation of tricalcium phosphate ceramic combined with tetracycline HCL root conditioning in treatment of periodontal osseous defects. Med. Cairo Univ. PP. 195-205.

22. Santiago Junior JF, P. E., Verri FR, de Carvalho PS. (2013): Mater Sci Eng C Mater Biol Appl. PP. 33, 14.

23. Shatkin TE, Shatkin S, Oppenheimer AJ, et al. (2003) A simplified approach to implant dentistry with mini dental implants.Alpha Omegan; pp. 7-15.

24. Bulard RA (2002): Mini implants. Part I. A solution for loose dentures. J Okla Dent Assoc; pp. 42-46.

25. Ohrnell, L. O., Hirsch, J. M., Ericsson, Iand Bränemark (1988): Single teeth rehabilitation using ossteointegration, A modified surgical and prosthetic approach. Quintessence international, PP. 871-872.

26. Becker, W.; Becker, B. E. (1995): Replacement of maxillary and mandibular molars with single endosseous implants restorations: a retrospective study. The Journal of prosthetic dentistry, PP. 74, 51-5.

27. Zahran A. (2008): Clinical evaluation of the OsteoCare Mini and Midi implants for immediate loading of mandibular overdentures. Imp Dent today; 2:154-59. 
28. Colomina, L. E. (2001): Immediate loading of implant-fixed mandibular prostheses: a prospective 18-month follow-up clinical study--preliminary report. Implant dentistry.

29. Kostic M, Krunic N, Nikolic L, et al. (2011): Influence of residual monomer reduction on acrylic denture base resin quality .Hem Ind65: 171.

30. Olate S, Lyrio MC, De Moraes M, Mazzonettor, and Moreira rw. (2010): influence of diameter and length of implant on early dental implant failure. J oral maxillofacial surg, pp.414-441.

31. Kalachev YS, iordanov PI, chaprashikian OG and Mano- hin E (2001): measurmaent of the magnitude of the occlusal forces during articulation. Folia med (Plovdiv); pp. 97-100.

32. Elena Preoteasa, Ana-Maria Cristina Tancu, Cristina Teodora Preoteasa (2014): Retention.sil as silicone matrices for implant overdenture, Carol Davila University of Medicine and Pharmacy, Bucharest, Romania, sky meeting.

33. Elena Preoteasa, Cristina Rizea, Florin Obadan Carol Davila (2014): MiniSky overdenture - microbial plaque adherence, University of Medicine and Pharmacy, Bucharest, Romania Manager of Bredent Medical, Bucharest, Romania sky meeting 2014. 